\title{
FENOMENOLOGI ALFRED SCHUTZ: STUDI TENTANG MOTIF PEMAKAIAN PECI HITAM POLOS
}

\author{
Alen Manggola ${ }^{1}$, Robeet Thadi $^{2}$ \\ UIN Sunan Kalijaga Yogyakarta ${ }^{1}$ \\ Universitas Islam Negeri Fatmawati Sukarno Bengkulu ${ }^{2}$ \\ manggolaa@gmail.com ${ }^{1}$
}

\begin{abstract}
ABSTRAK
Tujuan penelitian untuk mengetahui bagaimana fenomenologi pemakaian peci hitam polos oleh masyarakat Bengkulu. Metode penelitian ini menggunakan penelitian kualitatif bertradisi interpretif. Hasil penelitian menunjukkan bahwa pemilihan motif pemakaian peci hitam polos menjelaskan adanya pengaruh budaya/trend dan kenyamanan sebagai motif pemakaian peci oleh pemakainya, dan juga merupakan bentuk komunikasi simbol eksistensi. Simpulan penelitian bahwa motif pemakaian peci hitam polos sudah menjadi trend budaya masyarakat umunya. Kesimpulan dari penelitian ini yaitu motif pemakaian memberikan penjelasan bahwa budaya, sejarah, keindahan dan kenyamanan mampu mengalahkan kehadiran kreasi baru dalam produk yang sama, seperti eksisnya peci hitam polos di Bengkulu.
\end{abstract}

Kata Kunci: Fenomenologi Alfred Schutz, Motif, Peci Hitam Polos.

\section{ABSTRACT}

The purpose of the study was to determine the phenomenology of the use of plain black caps by the Bengkulu people. This research method uses qualitative research with an interpretive tradition. The results showed that the choice of motif for wearing a plain black cap explains the influence of culture/trend and comfort as a motive for wearing a cap by the wearer, and is also a form of communication as a symbol of existence. The conclusion of the study is that the motif of wearing plain black caps has become a cultural trend of the general public. The conclusion of this study is that the motive for use provides an explanation that culture, history, beauty and comfort can defeat the presence of new creations in the same product, such as the existence of plain black caps in Bengkulu.

Keywords: Alfred Schutz Phenomenology, Motif, Plain Black Cap. 


\section{PENDAHULUAN}

Peci merupakan salah satu kebutuhan primer sebagian orang yang memakainya, dan juga budaya di tanah Indonesia. Peci yang menjadi budaya nasional alih-alih sebagai pakaian yang menjadi tradisi, hal tersebut tentu akan mempengaruhi meningkatnya produksi peci. Potensi pelestarian budaya berpeci akan sangat meningkat. Artinya kebutuhan akan pemakaian peci tetap stabil dari mulai negara Indonesia berdiri. Seiring berkembangnya teknologi sangat memudahkan setiap pengusaha peci memproduksi peci dan juga jenis peci. Namun uniknya adalah jenis peci hitam polos tetap lestari pemakaiannya dikalangan masyarakat. (Hadiwijaya, 2019)

Peci hitam polos adalah istilah lain dari penutup kepala, tentu sering juga digunakan oleh pria muslim untuk acara keagamaan maupun acara resmi lainnya, sehingga berpeci tidaklah asing dalam dilingkungan sosial Indonesia. Peci hitam polos memiliki nilai luhur yang tinggi, dari sebuah nilai keagamaan menjadi sebuah nilai ideologi berbangsa. Selain itu peci hitam polos juga mampu memasuki wilayah pemikiran simbolis para pemimpin perjuangan Indonesia sejalan dengan perjalanannya. Hal menarik juga dapat melihat sejarah salah satunya Soekarno sebagai pencetus lahirnya Pancasila sebagai orang yang mengeksiskan peci sebagai simbol nasionalisme. (Hadiwijaya, 2019)

Terlihat menarik memang ketika mengambil hubungan antara sebuah peci dengan Pancasila sebagai dasar negara. Sehingga, dikenal dengan peci Soekarno juga merupakan salah satu simbol budaya pada suatu daerah, termasuk di Bengkulu yang masih lestari hingga sekarang. Berpeci dalam kegiatan kemasyarakatan atau yang bersifat sosial di Indonesia termasuk bentuk simbol pergaulan yang setara dan sederhana.

Hal tersebut dapat dilihat pada bentuk peci yang hanya tediri satu unsur warna hitam polos, dan juga bentuk pecinya yang seperti tabung mengikuti kepala penggunanya. Banyak hal yang positif dapat dipancarkan oleh bentuk dan warna peci pada mata sosial. Maka, hal tersebut memberikan nilai yang tentu berbeda, dengan tampilannya yang memukau mampu menghipnotis untuk pemersatu dalam kelompok sosial yang juga menampilkan budaya berpeci hitam polos.

Betapa menariknya fenomena yang terjadi, sebagaimana diketahui bahwa harga peci hitam polos tergolong cukup mahal apalagi terkait kualitas dan keindahannya. Akan tetapi itu semua tidak menyurutkan minat budaya memakai peci hitam polos dilingkungan masyarakat. Termasuk para pejabat ketika dalam acara pertemuan formal seperti dipemerintahan juga memakai peci hitam polos. Sehingga keeksisan pemakaian peci hitam polos termasuk fenomena yang memberikan rasa penasaran untuk diketahui apa motif pemakaian peci hitam polos tersebut. Mengapa minat pemakaian tetap pada peci hitam polos sedangkan peci dengan jenis yang cukup menarik juga banyak kita jumpai ditempat pembeliannya. Tentu setiap orang punya alasan kenapa tetap memilih peci hitam polos sebagai salah satu kebutuhan sandang mereka.

Mengupas tuntas prihal pemakaian peci hitam polos akan memberikan gambaran betapa urgennya untuk memakainya. Budaya peci hitam polos tentu sangat mendukung kemajuan budaya di Indonesia sebagai icon. Sebab, peci polos hitam memberikan pengaruh yang sangat positif dikalangan masyarakat, selain sebagai keindahan akan tetapi sebagai penguat ukhwah yang membuktikan bahwa mendukung keberlangsungan tradisi masyarakat. Sehingga minat yang positif di 
kalangan masyarakat tersebut harus tetap hadir mewarnai lingkungan masyarakat, termasuk lestarinya pemakaian peci hitam polos.

\section{METODE PENELITIAN}

Penelitian termasuk penelitian kualitatif bertradisi interpretif. Data penelitian diperoleh melalui metode: studi pustaka dan obeservasi, studi pustaka dipakai pengumpulan data terkait perkembangan peci hitam polos di Bengkulu, dan teori fenomenologi dalam ilmu komunikasi, baik berupa langsung dari buku atau jurnal sebagai literatur terkait dan juga sumber referensi yang diambil dari internet. Kajian pustaka merupakan bagian awal dari penelitian ini yang dimaksudkan untuk menghantarkan persoalan adanya fenomenologi pemakaian peci hitam polos yang tetap utuh dewasa ini meski banyaknya peci jenis lainnya yang dijual. Observasi atau survei dilakukan di berberapa daerah di Bengkulu untuk melihat fenomena yang terjadi dilapangan terkait pemakaian peci hitam polos seperti ketika sholat berjama'ah di masjid, acara masyarakat, dan di beberapa lembaga ataupun ormas.

Metode analisa yang digunakan adalah dengan mengkaji motif Alfred Schutz dengan tipe "Tujuan Pemakaian" dan "Sebab Pemakaian". Jadi, ada dua aspek yang akan dianalisa yaitu "tujuan dan karen". Maka sesuai dengan jenis data yang ada, dalam penelitian ini digunakan teknik analisis deskripsi kualitatif, dengan pengertian bahwa pengolahan data dipaparkan secara deskriptif. Sedangkan urutan analisisnya meliputi paparan data dan sajiannya, penganalisaan dan penarikan kesimpulan. Hasil analisis yang disimpulkan dari data-data dapat dijadikan dasar melakukan penelitian selanjutnya kepada arah yang lebih detail.

\section{HASIL DAN PEMBAHASAN \\ Teori Fenomenologi Alfred Schutz}

Teori yang digunakan adalah teori fenomenologi yang dikemukakan oleh Alfred Schutz. Inti pemikirannya adalah bagaimana memahami tindakan sosial (yang berorientasi pada perilaku orang atau orang lain pada masa lalu, sekarang dan akan datang) melalui penafsiran. Untuk menggambarkan seluruh tindakan seseorang, maka Schutz mengelompokan dalam dua tipe motif, yaitu: (1) Motif tujuan (In order to motive); (2) Motif karena (Because motive). (Schutz, 1967).

Pada teori ini mengupas terkait tujuan dan sebab pemakaian peci hitam polos dikalangan masyarakat. Teori akan memberikan arah yang jelas terkait alasan sebagai dasar motif pemakaian peci hitam polos. Sebab setiap orang tentu mamiliki alasan dan tujuan mengapa melakukan sesuatu. Sehingga, pengetahuan terkait motif fenomena pemakaian peci hitam polos tergambar sebagai bentuk upaya pelestarian budaya positif. Dengan mengetahui bahwa peci hitam polos sangat bermanfaat bagi sebagian besar masyarakat, akan membuat minat dan percaya diri meningkat ketika memakainya. Tentu banyak motif yang meuju kepada fenomena pemakaian peci hitam polos. Semua akan dijabarkan berdasarkan teori yang digunakan untuk lebih rincinya terdapat pada pembahasan.

Berpedoman pada teori Alfred Schutz, ada dua kelompok pembahasan pada paparan tulisan ini, sejalan dengan teori yang dikaji sebagai pengarah untuk mencapai tujuan penelitian. Pertama pembahasan terkait khusus aspek motif "Tujuan", yaitu tujuan pemakaian peci hitam polos di Bengkulu. Kedua pembahasan terkait aspek motif "Karena" yaitu sebab membuat mereka memakai 
peci hitam polos. Sehingga kedua motif ini juga akan dijelaskan hubungannya yang membuat kajian lebih dalam sesuai teori yang di kemukan Alfred Schutz.

\section{Aspek Motif "Tujuan" (In Order to Motive)}

Penelitian terkait motif "Tujuan" dilakukan pada tiga objek atau moment yaitu masjid, acara kemasyarakatan, dan ormas atau dan lembaga. Hal demikian dilakukan pengamatan ditiga objek penelitian tersebut yang dipilih karena menjadi sorotan dalam penggunaan peci hitam polos. Berikut pemaparan teori berdasarkan fenomena yang ada pada motif tujuan orang memakai peci polos:

Pertama, saat sholat ke masjid, ada dua maka yakni rapi dan makna eksis. Pada konteks rapi dimaknai rapi saat menghadap Tuhan. Menyukai warna dan bentuk menimbulkan rasa sehingga terlihat rapi, karena menghadap Allah harus rapi dan makna peci merupakan bentuk kesopanan beribadah. Warna yang menarik sesuai dengan warna rambut yaitu hitam polos, tentu akan memberikan daya tarik yang sepadan dengan fungsinya. Paradigma peci juga muncul pada mereka yang suka beribadah menggunakan peci hitam polos. Peci menjadi bentuk upaya pnghormatan atau etika dalam melakukan ibadah kepada Allah. Tentu bentuk etika yang dimaksud tidak meninggalkan dari keindahan berpakaian dan kepercaya dirian seseorang akan meningkat ketika menghadap sang pencipta dengan kondisi indah. Allah menyukai keindahan yang dilakukan oleh hambanya termasuk memakai peci hitam polos sebagai bentuk upaya yang dilakukan.

Pada konteks terlihat eksis menggambarkan. Bahwa peci polos walaupun sebagian masyarakat terbiasa sejak kecil memakai peci hitam polos dan hanya peci hitam polos yang disukai. Sehingga kebiasaan dapat memberikan eksistensinya pada dunia lingkungan masyarakat. Sebagaimana tujuan pemakaian peci hitam polos oleh sebagian orang khususnya Bengkulu. Ketika keeksisan telah tercapai maka bentuk kenyamanan akan terlihat. Telebih kebiasaan sebagai sebab seseorang untuk mencapai tujuannya. Jadi tujuan akan memperkuat prinsip seseorang pada hal atau sesuatu yang ia sukai dan itu membuat kenyamanan yang lebih diakui masyarakat. Sehingga pentingnya keeksisan bagi seseorang untuk dirinya terhadap lingkungannya, termasuk memakai peci hitam polos.

Kedua,saat acara kemasyarakatan. Ada tiga makna yang diberikan oleh masyarakat pemakai peci hitam polos yakni kenyamanan tampil, adaptasi lingkungan dan adaptasi budaya. Pada konteks kenyamanan tampil, pemakai peci hitam polos memaknai terlihat rapi dan cocok dimana saja termasuk acara musibah dan pernikahan. Pandangan memakai peci hitam polos tidak hanya dilakukan ketika hendak sholat di masjid, akan tetapi nilai yang diungkapkan oleh peci hitam polos juga sangat cocok untuk berbagai kegiatan massa terkhusus dilingkungan masyarakat. Akan merasa ada yang kurang ketika seseorang berbeda dengan orang lain secara penampilan meskimenarik akan tetapi nilai kebersamaan akan lebih memberikan nilai dihargai oleh mereka yang tidak jauh berbeda penampilannya. Pola kebiasaan rapi dan penyesuain diri akan sangat mudah memberikan nilai positif terhadap orang lain. (Kuntowijoyo, 1987).

Pada konteks adaptasi lingkungan. Pemakai peci hitam polos memaknai bahwa lingkungan memberi pengaruh yang sangat besar pada diri seorang terkait apa yang akan ia lakukan. Pengaruh lingkungan akan memberikan kebiasaan sejalan dengan dimana ia berada. Tentu kebiasaan itu akan menjadi budaya dalam aktifitasnya, akan terasa berbeda ketika berlawanan dengan kebiasaan tersebut. 
Sehingga ia akan terbawa arus lingkungan yang juga sama dengan individu lainnya yang berada di lingkungan tersebut. Sebagaimana pemakaian peci hitam polos di masyarakat Bengkulu, karena diantara mereka menyampaikan bahwa lingkungan telah memberikan pengaruh yang kuat terhadap keputusan untuk juga memakai peci hitam polos. Terlebih lagi mereka yang sudah berkeluarga tentu memakai peci hitam polos sudah merasa mengharuskan, tentu berbeda dengan anak muda yang belum berkeluarga. (Hadiwijaya, 2019).

Sementara pada adaptasi budaya, pemakai peci hitam polos memaknai dengan memakai peci hitam polos memiliki kebiasaan yang sama dengan mereka sebagai anggota masyarakat lingkungan akan lebih mudah berbaur dibanding memiliki kebiasaan yang berbeda. Sehingga motif tujuan menggunakan peci hitam polos salah satu diantaranya adalah agar mudah berbaur dengan lingkungan. Hal tersebut menjadikan seseorang diakui sebagai anggota kelompok kecil dalam komunikasi singkat ketika bertemu. Pembiasaan atau adaptasi merupakan pilihan yang tepat bagi seseorang untuk memudahkan hubungan antar individu.

Ketiga,peci hitam polos dipakai oleh lembaga dan organisasi masyarakat. Pemakaian peci hitam polos memiliki makna melestarikan budaya organisasi masyarakat atau lembaga kemasyarakatan, terlihat rapi/formal dan percaya diri, dan Cirri khas. Pada makna melestarikan budaya ormas/lembaga, dapat dijumpai beberapa ormas Islam ataupun lembaga seperti lembaga pendidikan juga melegalkan memakai peci hitam polos dan bahkan suatu kewajiban. Ketika aturan memberikan titah memakai peci hitam polos di waktu tertentu maka program itu menjadi kewajiban dan bahkan membudaya bagi lembaga atau ormas. Terkait pemaknaan mengapa diwajibkan atau berlakunya aturan tersebut, hal itu dapat kita jumpai pada sebabnya. Sebab memberikan pilihan yang positif terhadap tujuan yang ingin dicapai suatu lembaga. Maka, tak sedikit ormas atau lembaga menjadikan aturan sebagai pelestari kebudayaan lembaga atau ormas termasuk pemakaian peci hitam polos. (Kuntowijoyo, 1987).

Pada makna memakai peci hitam polos terlihat rapi/formal dan percaya diri, bahwa terlihat rapi semua orang tentu menyukainya, terlebih akan bergabung pada individu di lingkungannya sebagai sebab. Tujuan ingin terlihat rapi menunjukan pola hidup yang peduli akan repon sosial ketika akan bersosial. Sebagaimana tujuan itu digandeng dengan agar terlihat formal. Tak asing bagi kita menyaksikan para pejabat atau akademisi memakai peci hitam polos ketika berlangsungnya acara formal. Tentu memakai peci polos hitam akan memberikan rasa percaya diri yang tinggi karena sejalan dengan budaya acara formal. Tentu mereka yang tidak sejalan dengan budaya formal pada suatu acara akan merasa ada yang kurang atau hal menjanggal hati ketika tidak melengkapi atribut termasuk memakai peci hitam polos. Anggapan negatifpun juga sering dirasakan, sebab dinilai tidak bersungguh-sungguh karena tidak mempeduikan kelengkapan dan kerapian atribut. (Susanto, 1997)

Makna sebagai cirri khas, akhir-akhir ini sering kita jumpai bahwa adanya peci hitam polos ditambah dengan logo ormas/lembaga, upaya sampai ada yang memberikan logo pada peci merupakan bentuk motif tujuan. Sebagai ciri khas mayoritas ungkapan yang disampaikan termasuk makna logo yang terdapat pada peci hitam polos. Pada ormas/lembaga tentu perlunya keeksisan yang memberikan ciri khas agar orang mengenalnya. Sehingga upaya yang dilakukan menjadi dasar pada motif tujuan dan sebab pemakaian peci hitam polos. Selain itu juga dikenal 
bahwa orang yang memakai peci adalah seorang Muslim. Maka identitas agamapun dapat dikenal melalui peci hitam polos tersebut. Orang akan mengenal ketika ada ciri khas yang diungkapkan melalui simbol yang membuat daya tarik tujuan mata melihat keberadaannya. Sehingga lembaga dan ormas akan dikenal melalui ciri khas tersebut, termasuk melalui logo pada peci hitam polos. (Hadiwijaya, 2019).

\section{Aspek Motif “Karena” (Because Motive)}

Selain motif tujuan, dalam teori fenomenologi juga merujuk pada motif "karena". Maka motif karena atau sebab terjadinya fenomena akan juga dipaparkan pada tulisan ini. Berikut pembahasan terkait motif "karena" berdasarkan teori fenomenologinya. (Wild dkk. Schutz, Alfred dalam John 1967).

Pertama, karena aturan. Beberapa lembaga dilatarbelakangi oleh beberapa budaya, termasuk budaya mengenakan peci hitam polos sebagai bentuk keseragamaan penampilan. Hingga budaya seragam tersebut menjadi aturan yang perlu dipatuhi oleh anggota lembaga. Seperti dibeberapa sekolah dasar, ormas Islam, acara upacara yang bersifat formal di hari besar nasional. Ketika ada yang tidak memakai peci hitam polos akan ada sanksi atau penampilan yang kurang maksimal dan juga kurang enak dipandang. Aturan mengharuskan mereka untuk mengenakan peci hitam polos sebab budaya dan permintaan sudah memberi penegasan yang kadang kala ada perasaan tidak enak ketika melanggar aturan tersebut. (Kuntowijoyo, 1987).

Kedua,karena kemauan sendiri. Selain dari aturan sebagai sebab memakai peci hitam polos, juga dapat kita jumpai dari beberapa orang disekitar kita mengenakan peci hitam polos dalam kesehariannya. Sebab yang membuat ia memakai peci hitam polos adalah karena keinginannya sendiri yang pada awalnya dimulai dengan ketertarikan dan sebagai peningkat percaya diri bahwa peci sebagai simbol. Setiap perasaan manusia tidak mampu diterka, bahwa ketertarikan pada model budaya juga memiliki alasan tersendiri. (Kuntowijoyo, 1987).

Ketiga, karena ikut-ikutan trend. Aturan dan keinginan sendiri mengenakan peci hitam polos merupakan sebab yang cukup memberikan pengaruh yang positif. Selain itu bahwa warna budaya disekitar mampu memberikan sugesti untuk membuat perasaan terasa dan otak berpikir. Sehingga trend pemakaian peci hitam polos disekitar dan selalu dijumpai juaga mampu mengharuskan seseorang untuk mengikutinya. (Kuntowijoyo, 1987).

Teori fenomenologi menjelaskan bahwa terdapat hubungan antara motif "tujuan dan motif "karena". Hubungan kedua motif dalam teori fenomenologi dapat diuraikan sebagai berikut, pertama bagaimana aspek tujuan menghasilkan atau merujuk pada aspek karena. Seseorang melakukan sesuatu tentu memiliki alasan yang disebut motif, dan motif akan membagi dua maksud yaitu adanya tujuan maka adanya sebab, demikian juga sebaliknya ada sebab tentu pasti memiliki tujuan, walaupun sekedar ikut-ikutan hal itu sudah bisa menjadi motif dalam ilmu komunikasi. (Schutz, 1967) 


\section{SIMPULAN}

Berbagai fenomena pemakaian peci hitam polos yang terjadi di masyarakat Bengkulu memberikan daya tarik budaya yang cukup signifikan. Sebab keunikan yang hadir memberikan kesan positif bagi pemakai, dan yang melihatnya sebagai tampilan yang dihormati karena kesetaraan dan kesederhanaan. Maka, dari kajian fenomenologi dari segi motifnya memberikan hasil analisis diantaranya adalah sebab dan tujuan pemakaian peci hitam polos. Sehingga, fenomena kelanggengan trend memakai peci hitam polos dipengaruhi oleh budaya masyarakat pada umumnya.

Bagi masyarakat Bengkulu peci hitam polos termasuk peci yang mudah dijumpai ditoko penjualannya. Selain itu, kenyamanan dan daya tarik warna juga terasa cocok untuk digunakan diberbagai acara masyarakat, ataupun dalam kehidupan seharai-hari. Juga bentuk upaya melestarikan budaya muslim pada umumnya, dan juga budaya ormas sebagai bentuk hormat dan eksistensi mengikuti trend pada pendahulunya seperti para pejuang negara dan toko agama yang menggunakan peci hitam polos. Jadi, dapat disimpulkan motif pemakaian memberikan penjelasan bahwa budaya, sejarah, keindahan dan kenyamanan mampu mengalahkan kehadiran kreasi baru dalam produk yang sama, seperti eksisnya peci hitam polos di Bengkulu.

\section{DAFTAR PUSTAKA}

Hadiwijaya, D. (2019). Kopiah/Peci sebagai Salah Satu Atribut Identitas Bangsa Indonesia. Journal of Applied Science (JAPPS). 1(2). 031-040. 10.36870/japps.v1i2.50

Kuntowijoyo, K. (1987). Budaya dan Masyarakat. Yogyakarta. PT. Tiara Wacana

Liliweri, A. (1991). Memahami Peran Komunikasi Massa dalam Masyarakat. Bandung. PT Citra Aditya Bakti

Marissan, M., \& Wardhani, A., C. (2010). Teori Komunikasi Massa. Bogor. Ghalia Indonesia

Mulyana, D. (2001). Metodologi Penelitian Kualitatif. Bandung. PT. Remaja Rosdakarya

Mulyana, D. (2007). Ilmu Komunikasi Suatu Pengantar. Bandung. PT Remaja Rosdakarya

Rackhmat, J. (1991). Metode Penelitian Komunikasi. Bandung. PT Remaja Rosdakarya

Richard, W., \& Turner, L. H. (2008). Pengantar Teori Komunikasi Analisis dan Aplikasi. Jakarta. Salemba Humanika

Schutz, A. (1967). The Phenomenology Of The Social World. Illinois. Northwestern University Press

Wild, W., (Schutz, Alfred dalam John 1967). The Phenomenology of the Social World. Illinois. Northon University Press

Sobur, A. (2003). Semiotika Komunikasi. Bandung. PT. Remaja Rosdakarya

Sundjaja, S. D. (1997). Teori Komunikasi. Jakarta. Univesitas Terbuka

Susanto, A. (1997). Pengantar Sosisologi dan Perubahan Masyarakat. Bandung. Bina Cipta 